Argumentação Jurídica e a Imunidade do Livro Eletrônico $\mathcal{H}$ umberto Ávila

Os Danos à Pessoa no Direito Brasileiro e a Natureza da sua Reparação Gudith Martins-Costa

O Limite Constitucional da Autonomia Privada: O Princípio da Solidariedade Social como Limite à Liberdade Contratual .............................................................................................. 209 Luciane Lourdes Webber $\mathcal{L}_{\text {oss }}$

O CDC e os Serviços Bancários no Brasil Luciano $\mathcal{B}_{\text {enetti }} \mathcal{I}_{\text {imm }}$

O Direito ao Livre Desenvolvimento da Personalidade na Alemanha e Possibilidades de sua Aplicação no Direito Privado Brasileiro

Marcos de Campos $\mathcal{L}$ udwig

A Publicização da Noção de Pessoa Jurídica como Fator de Construção da Dogmática do 'Estado de Direito'

$$
\text { Maren Guimarães Iaborda }
$$

A Redução Voluntária de Capital Social nas Sociedades Anônimas

Maria Honorina de Bittencourt Souza / Michel Zavagna Gralha

El Estado Penal Neoliberal

Sebastián Rodrigo Ghersi

EMENTA: "Doação Inoficiosa - Art. 1.176 do CC - Querela Inofficiosae Donationis Requisitos"

$$
\text { Carlos Thompson Flores }
$$

\section{Espaço Público para o Diálogo Franco e Aberto, Pluralista e Democrático*}

\author{
Eduardo $\mathcal{K}_{\text {roeff }}$ Machado Carrion
}

Diretor da Faculdade de Direito da UFRGS na Gestão do Centenário (1966/2000) 
nossos arquivos, encontraríamos a pasta $\mathrm{n}^{0} 97$ de Getúlio Vargas e nela uma prova da disciplina de Filosofia do Direito de 1906 que deixa transparecer uma preocupação social, em que há uma verdadeira antecipação da visão de Estado que foi implementada a partir dos anos 30, um Estado preservando a propriedade privada, mas intervindo com políticas sociais para abrandar as grandes desigualdades sociais.

É verdade, toda essa herança da Faculdade foi obra de grandes personalidades, de grandes energias, mas essas personalidades, essas energias foram potencializadas pelos banco escolares desta escola. Mas não gostaria de falar apenas a respeito dessas grandes personalidades, dessas grandes energias. Gostaria de referi me àquele trabalho larvar, àquele trabalho gran de, porque pequeno, permanente, porque cotidiano. Em outros termos, a respeito de noss contribuição para a formação da consciência republicana no Estado e no país. Seguramente contribuímos para a transição para o estado de direito no Rio Grande do Sul.

Temos, no Rio Grande do Sul, uma tradição guerreira, de lutas intensas, violentas. Noss história é marcada por essa realidade. Entretanto, ajudamos, aqui na Faculdade de Direito, no combate pela justiça, na defesa dos predicado do direito, a transitar dessa situação para o estado de direito. Ajudamos a transcender a guerr para construir a política. A política não prescinde da norma jurídica, ela tem de se dar no leito da norma jurídica, para adquirir a necessária regularidade e disciplina instauradas pela norma política. Nós ajudamos assim a construi o estado de direito no Rio Grande do Sul. Ma não só isso. Uma marca da Faculdade é também o seu direcionamento, a sua vocação para o direito público que se expressa nessa conjugação de que falava José Salgado Martins entre a investigação científica e a inserção social e política revelada pela presença de grandes publicistas e grandes políticos. Mais ainda. Nós

temos algo que parece marcar nossa trajetória $e$ que precisa ser destacado. Trata-se do espírito de tolerância, de debate democrático e pluralista. Tolerância na diversidade.

Sabemos todos que a Faculdade de $\mathrm{Di}$ reito surgiu, em grande parte, graças ao descortino da elite política e cultural do Estado, sob influência da ideologia positivista, destacando-se o papel fundamental do patriarca da República gaúcha Júlio Prates de Castilhos e o do então Presidente do Estado Antônio Augusto Borges de Medeiros, tendo como grande idealizador o desembargador Carlos Thompsom Flores a quem rendo justas homenagens. Pois bem, essa influência marcante do positivismo na origem da nossa escola, marcante de maneira geral na criação dos cursos superiores no Estado do Rio Grande do Sul, positivismo esse que foi um instrumento de modernização do Estado, embora refletindo, é verdade, uma visão tutelar das relações entre Estado e sociedade civil, essa hegemonia inicial do positivismo na nossa escola não foi incompatível com a diversidade, o debate, a polêmica. A primeira aula desta escola foi proferida por Plínio Casado, titular da disci plina de Direito Público e Constitucional, no dia 4 de maio de 1900 , aula inaugural essa em defesa do estado de direito. A honra que coube ao jovem Professor Plínio Casado, futuro ministro do Supremo Tribunal Federal, revela, nas nossas origens, essa capacidade de conviver com a diferença e a diversidade. É verdade que houve momentos de intolerância também nesta casa. Mas fomos sobretudo vítimas da intolerância em diversos momentos. Lembro a destituição de seus cargos de dois eminentes professores: Ajadil de Lemos e Brasi Rodrigues Barbosa pelo movimento de 1964 . O espírito de tolerância, fundamental para a convivência democrática, que se expressa já nessa aula inaugural, marca nossa trajetória já centenária.

A atual gestão que tem a responsabilidade das comemorações do centenário que, a rigor, iniciaram-se naquela noite memorável de 9 de novembro de 1998 e que prosseguem ao longo do ano 2000, mas que têm como ápice a jornada do dia de hoje que, na realidade, iniciou no dia de ontem e está se encerrando nesse magnífico ato de homenagem das entidades profissionais e culturais na área jurídica, está procurando resgatar a idéia de tradição e de modernidade que foi também uma marca da nossa escola desde sua origem.

Recentemente, recuperamos o símbolo desta escola, a logomarca, cujo primeiro registro encontramos em 1908. Um trapézio que é um triângulo inacabado, simbolizando a idéia de uma obra ainda não concluída, uma tarefa a realizar-se, uma abertura para o futuro. Mas sobretudo a imagem da justiça sem os olhos vendados. Algo inovador e surpreendente na época, quando tradicionalmente a justiça era representada com os olhos vendados. A deusa grega da justiça, Têmis, era ora representada com os olhos vendados, ora sem os olhos vendados. $\mathrm{Na}$ Corte Internacional de Haia, a justiça está igualmente representada sem os olhos vendados. Que bela expressão de modernidade nessa representação! Isto é, uma justiça atenta à realidade do presente, às angustias do cotidiano, com os olhos abertos para as preocupações do homem comum. Uma justiça que reconhece as desigualdades de fato e percebe que uma norma de igualdade pode ser fonte de uma flagrante injustiça se não houver a necessária mediação dos chamados operadores do direito no sentido de adequar a norma abstrata às circunstâncias concretas da vida prática. Pois bem, essa simbologia estava presente em nossas origens. Então, quando falamos hoje em tradição e modernidade, na realidade é modernidade porque é tradição e é tradição porque é modernidade, como se o passado se confundisse com o presente e o presente se confundisse com o passado para alavancarem a construção do futuro. A Faculdade de Direito da UFRGS nas- ceu como Faculdade Livre de Direito. Ela foi uma faculdade livre porque de direito, já que não há liberdade sem o parâmetro jurídico, e ela foi uma faculdade de direito porque livre, $j$ á que não há direito sem liberdade. Faculdade livre e faculdade de direito, duplamente livre e duplamente de direito.

Nesta centenária trajetória que honra a história do Rio Grande do Sul e a história do país, mantivemos continuamente a excelência acadêmica. Todos os indicadores públicos ou privados atestam a excelência acadêmica $\mathrm{e}$ isso vem sendo-reconhecido pelo mundo jurídico regional e nacional. A par do ensino de graduação e de pós-graduação, em nível de excelência, mantemos uma intensa atividade de pesquisa acadêmica e de extensão universitária conjugando as três grandes missões da universidade, cristalizadas em mandamento constitucional: ensino, pesquisa e extensão, mas ensino, pesquisa e extensão em nível de excelência convém ressaltar.

A Faculdade de Direito da UFRGS não se limita apenas a isso. Com muita razão foi dito pelo Vice-Reitor da UFRGS, Professor Nilton Rodrigues Paim, que somos um dos quatro pilares da criação da Universidade de Porto Alegre, atual Universidade Federal do Rio Grande do Sul, mais precisamente o pilar humanístico. Mas somos mais do que isso. Esta manhã, na sessão solene da Congregação desta Faculdade, abrindo as comemorações do centenário sua excelência o Governador do Estado Olívio Dutra destacou "a longa, profunda, respeitável história de contribuição para a construção dos traços fundamentais da organização do Estado, do estado democrático de direito, nesta unidade da federação, o Rio Grande do Sul, e no nosso país" e que se tratava "não apenas da celebração dos 100 anos de um dos quatro esteios iniciais da Universidade Federal do Rio Grande do Sul; temos aqui a celebração de valores fundantes da organização do Estado, da 
humanidade, da universalidade que precisam ser constantementes sublinhados, constantemente afirmados na prática cotidiana de todo mundo". Sim, temos uma responsabilidade histórica para com a sociedade gaúcha e a sociedade brasileira. Nós ajudamos em grande parte a construir a consciência republicana e democrática deste Estado e deste país. Esta é uma missão a que não podemos nos furtar, a par da excelência acadêmica do ensino, da pesquisa e da extensão.

Quero finalizar essas rápidas palavras para dizer da emoção e do agradecimento, da emoção pessoal como Diretor e do agradecimento da Faculdade de Direito às entidades que hoje nos homenageiam, às entidades profissionais $\mathrm{e}$ culturais na área jurídica que hoje nos homenageiam nesta noite.

Gostaria de expressar igualmente um agradecimento à sociedade gaúcha pela receptividade com relação a nossa comemoração, pelo carinho com que está sendo acolhida esta comemoração, para todos surpreendente. Sinceramente, nós da Faculdade de Direito não esperávamos tanta receptividade e tanto carinho, talvez porque subestimássemos a importância de nossa tradição, de nossa longa folha de serviços prestados ao Estado e ao país. Creio que é um reconhecimento que nos impulsiona, nos incentiva, nos potencializa para enfrentar as dificul- dades e os desafios do futuro, sem esquecer as agruras do presente. Sim, a Universidade Pública, em especial a Universidade Pública federal, vive um momento de intensas dificuldades. Universidade essa que não é simplesmente a construção deste ou daquele governo, mas é um patrimônio construído por sucessivas gerações e hoje seriamente ameaçado. Mas seguramente resistiremos nesta Faculdade de Direito como já o fizemos em muitos outros momentos. Relembro ainda, na segunda metade dos anos 60, a resistência representada pela Faculdade de Direito em face da famigerada reforma universitária, em face da tentativa de fragmentação da instituição universitária. Aqui faço minhas homenagens ao dr. Ruy Cirne Lima, então Diretor da Faculdade, com quem tive a oportunidade de conviver como Presidente do Centro Acadêmico André da Rocha. Nós sustentaremos sempre a luta pela Universidade Pública, preservando ao mesmo tempo a excelência do ensino, a qualidade da pesquisa e da extensão. E como Universidade Pública que o é, será também sempre um espaço público para o debate franco e aberto, pluralista e democrático, conforme aquele espírito de tolerância que marca a sua trajetória, dos grandes temas e questões nacionais e internacionais que angustiam a humanidade e a civilização neste alvorecer do próximo século.

Muito obrigado.

\section{Reflexões de um antigo aluno de Hannah Arendt sobre o conteúdo, a recepção e o legado de sua obra, no 250 aniversário de sua morte}

\author{
Celso Lafer
}

Li. $-\mathrm{I}-$ obra de Hannah Arendt (1908-1975) vêm crescendo continuamente. Atualmente, a irradiação dos temas centrais de sua reflexão é muito mais significativa do que quando estava viva e fui seu aluno de pós-graduação, na Universidade de Cornell nos EUA, em 1965.

Naquela época, ela era uma personalidade conhecida, mas controvertida, presente n vida universitária e intelectual norte-americana, tendo já transposto os circuitos acadêmicos, graças ao fundamental livro, de 1951, sobre o totalitarismo. Era, no entanto, vista com suspeita pela esquerda, por conta da qualificação, não apenas do nazismo, mas também do stalinismo como vertente de um ti po inédito de regime de dominação, caracterizado pela ubiqüidade do medo, instrumentado na organização burocrátca de massas e sustentado pelo emprego do terror e da ideologia. Tinha além disso adquirido notoriedade adicional por conta das vivas polêmicas suscitadas pelo relato do processo Eichmann e pelo conceito da "banalidade do mal", por ela cunhado em livro da década de 60 sobre o assunto. No livro, discutiu o descompasso entre a enormidade do crime do holocausto e a opaca irrelevância da personali-

dade do burocrata que o administrou com terrí vel eficiência.

Hannah Arendt era admirada por seu resgate teórico do papel da ação no espaço público, mas considerada por muitos como defensora nostálgica e anacrônica da polis grega e da herança clássica. Era percebida como pensadora idiossincrática que admirava a esperança do "novo", inerente ao fenômeno revolucionário, e ao mesmo tempo advertia sobre os seus descaminhos; que salientava, de um lado, a relevância da autoridade como categoria política, e de outro sublinhava o significado da desobediência civil como forma válida da resistência à opressão e de recuperação da obrigação política.

Em síntese, não havia consenso em torno da pertinência da sua obra para o entendimento do mundo contemporâneo, e prevalecia razoável desconforto em relação a uma pessoa que não se enquadrava nos cânones políticos usuais (esquerda/direita; liberal/conservadora, etc.), nem era facilmente identificável no âmbito das disci plinas acadêmicas (Filosofia, Teoria Política, História, etc.) "I somehow don't fit", observou a própria Hannah Arendt num importante colóquio sobre a sua obra realizado em novembro de 1972 . 